\title{
Reasearch of Reducing Agent
}

\author{
Haiquan Wang ${ }^{1, \text { a }}$ \\ ${ }^{1}$ Chemistry and Chemical Engineering \& Environmental College, Weifang University, Weifang, \\ Shandong, China \\ ahaiquan202@hotmail.com
}

Keywords: Reasearch; Oilwell Cement; Fluid Loss Additive; Synthesize

\begin{abstract}
Reducing agent is an important part of drilling fluid using oil and gas fields. Its function is to reduce amount of lost water of drilling fluid, and then the rheological properties of drilling fluid can be improved. This article outlines the research progress of water-based drilling fluid reducing agent in past years. Some problems about reducing agent have been pointed out.
\end{abstract}

\section{Introduction}

With the rapid development of science and technology, human demand for fossil fuels increased significantly, in order to meet the demand, the rise of offshore oil surveying process; due to drilling conditions of complex and varied, in the actual cementing construction in order to ensure cementing quality, The cement admixture standard has become a key factor. In the construction, if the cementing mud filter loss control is not good, it will lead to pollution of the reservoir, serious cementing operations will fail. Due to the large demand for oil in production and life, the shallow oil and gas storage rate drops sharply. How to develop the exploration technology of deep well and ultra deep well has become the primary task of China's oil development strategy. Due to the long duration of technology in the development, difficult, high investment problems and deep wells have a greater risk of operation, so in the actual mining not only for equipment, pipe quality and cement wells cement cement admixture requirements more and more High and the cementing process also put forward a higher standard[1].

\section{Research and Development History of Cement Slurry Fluid Loss}

In the 1960s, the harm of cement slurry loss caused widespread concern of foreign scientists, began to study a large number of cement slurry filter loss agent. In order to meet the needs of safe cementing and protection of oil and gas, China began to study a lot of fluid loss in the 1980s, the rapid development of the research process, the trend was a linear upward trend. Into the 90's, its research enthusiasm is fanatical, a series of fluid loss products occupy the Chinese market, according to incomplete statistics have more than 30 brands of fluid loss agent, these efforts not only protect China's cementing technology, but also opened the international market, so that China's manufacturing industry will enjoy worldwide fame.

\section{Cement Fluid Loss Agent in The Field of Oil Formation Process}

In the formation of oil well cement powder loss agent, the theoretical research on the following several important points.

\section{Physical Filling Blockage.}

In the condition is a certain pressure, there will be a phenomenon: microcracks in the cake will have a lot of fluid loss particles into the cement particles in the random collection. So that the formation of cement cake, it has a low permeability of the excellent characteristics, so that a good control of the penetration rate, thereby reducing the loss of cement slurry.

Increase the Liquid Viscosity.

A large number of cement slurry will be added to the polymer polymer will increase its viscosity, greatly increasing the resistance of free liquid loss, so as to achieve the effect of reducing the loss of 
cement slurry. However, this method will lead to the decline in the flow performance of cement slurry, to the actual operation of the great difficulties, there are many problems: such as the replacement efficiency is not high. Therefore, this method is rarely used alone.

\section{Adsorption - Dispersion.}

The polymer powder loss agent added to the cement slurry, the polar groups have adsorbed on the surface of cement particles in the characteristics of adsorption hydration layer formation, there will be tissue cement particles automatically coagulation The effect of maintaining a moderate distribution of particles. Adsorption of macromolecular cement particles on the surface of the double layer structure will change, increase the zeta potential, to prevent the flocculation, the occurrence of precipitation, to promote the stability of the cement particles are distributed.

\section{Varieties}

At present, there are more varieties of fluid loss at home and abroad, and the mechanism of action of fluid loss is different, which is divided into two major categories [2]: solid particulate material and water-soluble polymer material. In addition, the use of special cement system can effectively reduce the amount of loss, which applied to the needs of special downhole conditions.

\section{Granular Materials.}

Bentonite is used as the earliest particle raw material for cement slurry. The diameter of the clay particles is very small, between the cement filter cake can be free access, resulting in reduced permeability of the filter cake to ensure that the loss of cement slurry loss. In addition to this material, there are carbonate fine powder, quartz powder, diatomaceous earth, barium sulfate fine powder and thermoplastic resin.

Crinkelmeyer et al. [3] such as particles with particle diameter of $1 \sim 100 \mu \mathrm{m}$ colloidal clay particles dispersed in water-soluble carboxymethyl cellulose, and several polyvalent metal cation interaction to produce cement or drilling fluid fluid loss agent, Application of the best temperature is the temperature.

Burkhalte et al. [4] used an organoclay that could be suspended in a cellulose derivative or an acrylamide copolymer and was used in combination with three substances: liquid hydrocarbons, surfactants and dispersants. The role of this system is: does not cause the precipitation of cement slurry, and the preservation time can be more durable.

Olaussen et al. [5] added 5\% to 20\% silicate colloidal suspension to form a cement slurry. Silica ash is characterized by: smaller particle size and larger surface area, the role is: the loss of cement slurry filter can effectively prevent the gas channeling, so that the slurry is more solid. The addition of peanut shell powder can make the cement slurry in the harsh high permeability formation is not missing, thereby reducing the rheological properties of cement slurry, so that environmental pollution, resulting in a uniform consistency, compressive strength enhanced cement slurry. The peanut shell powder is mixed with the fluid loss agent by the method of compounding, and the loss of filtration is greatly enhanced when used. Forrest [6] suggested that the amount of peanut shell powder in the range of $0.6 \%$ to $5.5 \%$ is appropriate, peanut shell powder particle size between 30 to 510 (in $10 \%$ peanut shell powder).

\section{Water-Soluble Polymer Materials.}

Modification of natural high polymer. Plant photosynthesis of the polymer is a natural polymer, is a renewable resource, features: low price and easy degradation. Because of its advantages, it is widely used in the petroleum industry. Water-soluble natural polymer as a filter-reducing agent has just begun to be widely used in drilling fluid, and with the development of cementing technology, it has gradually become the main material of oil-cement mud loss. Cellulose, starch, tannin and other water-soluble polymer can be used for oil well cement, because natural products have many advantages, so the modification of these materials or composite applications become a hot spot for material research.

\section{Cellulose.}

Cellulose ethers are commonly used materials for oil well cement. Cellulose ether material using the principle is: by how much the amount of cement slurry loss in the appropriate range of fluctuations. Due to the large addition of cellulosic materials, it increases the consistency of the cement slurry, which can lead to agitation and pumping stops. 


\section{Starch.}

Thickening, gelatin, bonding and film formation is the main performance of starch, starch has a low price, wide supply characteristics, is widely used in the national economy. In the oil industry, the main purpose of starch is drilling fluid. As the graft or block copolymer can better modify the performance of starch, so the expansion of the use of a crucial role.

Tannins.

Polyphones and carboxyl groups are the main constituents of tannins. Tannins are divided into two kinds: condensed tannins and hydrolyzed tannins. Drilling fluid treatment agent is the largest use of tannin in petroleum technology, through the modification of tannin modified by grafting, is used as an oil well cement loss agent. Grafting modified tannin characteristics: loss of filtration and strong anti-gas channeling ability, at high temperatures $215^{\circ} \mathrm{C}$ can be assured that use.

Water-soluble synthetic polymers. Although there have been new reports that the development of oil well cement admixture is better water-soluble synthetic polymer fluid loss agent. But because of their existence temperature, poor salt resistance and other problems; there are high product costs, in the market competitiveness at a disadvantage.

The synthesis unit of the synthetic polymer powder reducing agent is a vinyl monomer. In general, we use 2-acrylamido-2-methylpropanesulfonic acid (AMPS), acrylic acid (AA), methacrylic acid as anionic monomer: acrylamide (AM), N, N-dimethylacrylamide, N-methyl-N-vinylacetamide (VMAA), methyl vinyl ether, maleic anhydride as nonionic monomer; 4-methacrylamide oxypropyltrimethylammonium chloride as cation monomer.

\section{Special Cement Systems.}

"Special oil well cement" is a special performance of the well cement, the main products are: latex cement. Latex cement has a good performance of reducing loss and anti-channeling performance [7]. The diameter of the latex polymer particles is about 0.05 to $0.5 \mu \mathrm{m}$. Portland cement by adding latex, the late formation of latex cement system, it has a better loss of filtration performance.

Styrene / Butadiene copolymer use temperature up to $176^{\circ} \mathrm{C}$ is the latest product of latex, adding various surfactants to further improve its performance [8].

\section{Role of Cement Slurry Filter Loss in the Field of Oil Wells.}

A large number of water loss of cement slurry not only cause damage to the formation, mainly the formation of precipitation clogging the formation; and will change the flow of cement slurry, so that thickening of cement slurry, increase pump pressure, causing great harm to the machine. In order to reduce and improve the mass of the cement slurry, it is necessary to use a slurry filter. The use of this oil cement additives, it will increase the reservoir capacity, reduce cementing accidents, improve the quality of cementing [9]. In order to adapt to different oilfield status, China has developed a large number of cement slurry filter loss agent, and different varieties of oil well cement powder loss agent in the oil field has been applied.

\section{References}

[1] B.Z. Huang: Professor Huang Baizong 's Oil Well Cementing Research (Petroleum Industry Press, China, 1998), p.24.

[2] Y. Luo, J. Zheng: Research Progress of Oil - water Slag Loss - reducing Agent at Home and Abroad, Speciality Petrochemicals, Vol. 5(1990), p.6.

[3] O.W. Crinkelmeyer, R.L Root and J.R. Shappe: U.S. Patent 4102400. (1978).

[4] Q. Wang: Research and Application of Oil Well Cement Loss - reducing Agent in China, Chemical Engineering of Oil and Gas Chem Eng Oil Gas, Vol. 21(1992) No.21, p.105.

[5] S.Olaussen and A. Bjordal: U.S. Patent 5149370. (1992).

[6] G.T. Forrest: U.S. Patent 5229019. (1993). 
[7] R.X. Yan: Water - soluble macromolecules (Chemical Industry Press, China, 1998), p.8.

[8] S.Gopalkrishnan: U.S. Patent 5262452. (1993).

[9] Mckenzie. Oil and Gas, Vol. 12 (1983) No.12, p.75. 